virus is different from the others; at any rate there is no case on record of direct communication of tick or mite typhus from one person to another, and, after all, the manner of conveyance of the diseases is by far the most important practical matter from the physician's point of view. Flea typhus is so closely related to louse typhus in its immunological and serological aspects that careful research will be needed to determine whether or not the virus of louse typhus can ever be transmitted by fleas. If this virus be transmissible by fleas it must be greatly attenuated in the process, since flea typhus is the one type which has never been found to be severe. There is no evidence that any of the non-epidemic typhus fevers has ever started in a louse-borne epidemic, so that although there may be some mental reservations regarding the relation of the fevers, practising physicians can safely base their action on the hypothesis that epidemic and non-epidemic typhus fevers are essentially distinct from each other.

\section{Differential Diagnosis}

I have already referred to the error into which $I$ fell eighteen years ago with regard to virulence; the truth is that tick typhus and mite typhus may be very mild or very severe. The same applies to a lesser extent to louse typhus, which is sometimes quite mild. Flea typhus alone has a consistent record of mildness so far, although severe or even fatal cases have been recorded. Another point which is sometimes relied on for differential diagnos's between the various forms of non-epidem:c typhus is the presence or absence of local necrosis at the site of infection associated with lymphangitis. This feature is sometimes present and sometimes absent, both in tick typhus and mite typhus; it cannot, therefore, be relied on as a point of distinction between the two fevers. Agglutination and animal inoculation tests are not always conclusive, so that when there is no positive evidence regarding the vector difficulty may arise at times in individual cases in distinguishing between the three types of non-epidem:c typhus.

On the other hand, there will seldom be any difficulty in deciding whether any given fever belongs to the epidemic or non-epidemic group if all the circumstances of each case or outbreak are invest:gated. After all, the chief concern of the medical man is to decide whether he is dealing with a disease which calls for extremely careful precautions to prevent spread to other human beings or with a disease not communicable from man to man.

Serological tests against two or more varieties of proteus $\mathrm{X}$ organisms will often be of great help in diagnosis, and knowledge of the local conditions will usually make it possible to be reasonably certain of the particular vector which is concerned.

We are now at an interesting stage of the investigation, and with so many intelligent observers at work throughout the world we seem to be rapidly approaching the time when the non-epidemic typhus fevers will be completely rescued from the small and rapidly diminishing group of fevers of unknown or doubtful aetiology. The most astonishing feature of the non-epicemic typhus fevers is that they escaped recognition so long in many parts of the world, in spite of their striking and characteristic features.

Volume XII of the Guide to Current Official Statistics of the United Kingdom is now available. It contains a list of the titles and prices of the statistical volumes issued during 1933 by the Governments of Great Britain and Northern Ireland, and an alphabetical index of their contents. Copies can be obtained from H.M. Stationery Office (1s. net, 1s. 5d. post free).

\section{THE MEDICINAL TREATMEN'T OF CHOREA (CALCIUM ASPIRIN) \\ BY}

\author{
N. MUTCH, M.D., F.R.C.P. \\ PHYSICIAN TO GUY'S HOSPITAL
}

Discussion will be confined to chorea of Sydenham's type in children. Debatable cases of adult hysteria, pregnancy chorea, and conditions such as Huntington's chorea with gross structural changes in the central nervous system have been excluded.

\section{General Considerations}

The anatomical basis of the disease is still uncertain, and such changes as have been described are attributable to pyrexia, capillary emboli from coincident endocarditis, or confusion in diagnosis with the choreiform varieties of epidemic encephalitis. The basal difficulty is that in its typical form Sydenham's chorea is not fatal. Practically all recorded post-mortems have been carried out on cases of rheumatic endocarditis and pericarditis complicated by chorea, and not on patients dead from chorea itself. The most careful histological research, with modern methods on a typical case, by $\mathrm{Shaw}^{28}$ did not reveal any morbid changes other than simple hyperaemia. It can be assumed, therefore, that the anatomical changes are negligible, and not such as to preclude complete recovery. If the patient is suitably rested and cared for, the spontaneous recovery rate approaches 100 per cent., so that the effect of a drug can only be assessed in terms of its ability to lessen the duration or severity of the attack. The average duration is usually accepted as s:x to ten weeks, but some cases drag on for months.

For greater discrimination some method of grouping is essentral.

1. Mild chorea, in which speech is not definitely affected and the patient can feed and dress himself with more or less difficulty.

2. Moderate chorea, in which coarse voluntary movements can still be performed, but the patient cannot feed or dress himself.

3. Severe chorea. Violence or pseudo-paresis now prevent all purposeful voluntary action. Bed boards and other protective measures are required.

Adopting a somewhat similar grouping Sutton ${ }^{29}$ records sixty-three undrugged cases.

\begin{tabular}{|c|c|c|c|c|c|}
\hline \multicolumn{4}{|c|}{ Group } & Average Duration & Extremes \\
\hline 1. Mild & ... & $\ldots$ & $\cdots$ & 35 days & 10-65 days \\
\hline 2. Moderat & & $\ldots$ & $\ldots$ & 46 & 19-120 days \\
\hline 3. Severe & ... & ... & ... & 67 & $30-180$ days \\
\hline
\end{tabular}

The general average was 47 days.

There is no reason to believe that the general characteristics of the disease have undergone any material change in the last eighty or ninety years. Already by $1846 \mathrm{H}$. M. Hughes $^{7}$ had dealt with the matter at Guy's. A few years later Sée $^{27}$ recorded an extensive clinical and aetiological analysis in Paris, and Trousseau discussed it at the New Sydenham Society. In 1874 Pye-Smith ${ }^{24}$ reviewed the Guy's Hospital figures again, and in 1897 Morley Fletcher ${ }^{18}$ did the same at St. Bartholomew's. The chief clinical features have remained constant throughout. The disease has persistently occurred about three times as commonly in females as in males. The age of maximum incidence has always been between eight years and puberty. Urban districts have been more affected than the country, and the association with articular rheumatism and inflam- 
mation of the heart has been uniformly common. The mortality has been steady at about 2 per cent. If these facts are borne in mind it becomes comparatively easy to discard most of the older methods as powerless to change the general course of the complaint.

\section{Therapeutic Measures}

Methods have been varied and ingenious, and routes of administration many.

By Mouth.-Sodium salicylate, arsenious oxide, mercury, antipyrine, aspirin, chloral, chloretone, trional, bromides, luminal, nirvanol and other hypnotics, thyroid, parathyroid, and iodine.

Subcutaneously.-Adrenaline, sodium cacodylate, Rosenow's antiserum, and varieties of antistreptoesccal sera.

Intravenously.-Novarsenobenzol, hypotonic saline.

Intramuscularly. Sulpharsphenamine, milk, typhoid vaccines, and T.A.I3.

Intrathecally.-Magnesium sulphate, colloidal silver, gentianviolet, 1 per cent. phenol, atoxyl, sodium salicylate.

Per Rectum.-Avertin and paraldehyde.

Various Measures.-The removal of tonsils and other foci of sepsis and irritation; the ketogenic diet.

Although most of these methods can be dismissed as useless a few call for special discussion.

\section{Nirvanol}

Nirvanol, or phenyl-ethyl-hydantoin, a near relation of the barbiturates, was first introduced as a hypnotic, but soon discredited because of its great tendency to produce skin eruption. It was reintroduced in 1919 by Roeder, ${ }^{25}$ in Germany, as a specific for chorea. Her results were confirmed in Germany (1924-5) by Schmal, ${ }^{26}$ E. Hefter, and Husler, ${ }^{8}$ and subsequently by a host of workers in Germany, America, and England. Even in 1932 its praises were still sounded, thirteen years after its introduction (Dennett and Wetchler ${ }^{4}$ ). It would appear to be quite established as a drug which shortens the attack in a useful proportion of cases, in spite of the adverse report from a minority of clinicians-for example, Weinfeld and Cohen. ${ }^{34}$ The treatment is drastic. A week is occupied in saturating the patient with the drug. Then follows a period of fever, rash, and severe constitutional disturbance. The method is not free from risk, and a certain number of deaths have been attributed to its use. It may cause serious leucopenia, loss of platelets, purpura, mucosal haemorrhage (Jones and Jacobs'), bloody diarrhoea, jaun. dice $\left(\operatorname{Keller}^{10}\right)$, severe lung complications (Piltz, ${ }^{22}$ also Jones and $\mathrm{Jacobs}^{ }$), and damage to the kidneys (Pilcher and Gerstenberger ${ }^{21}$ ).

These universally disagreeable and sometimes dangerous side actions preclude any general employment of the drug in private practice. In my personal experience the biochemical trauma produced by the drug has impressed me far more than its efficacy in controlling the chorea.

\section{Ketogenic Diet}

Increased muscular excitability in conditions of alkalosis and tetany led to the suggestion that, in a converse manner, hyperexcitability might be depressed by the production of artificial acidosis. With this end in view a diet containing an excessive proportion of fat is given. The ratio of fatty acid to glucose is made $2: 1$ and graduated until the ratio becomes $4: 1$. On this regimen acetone quickly appears in the urine, although the $p H$ of the blood and the plasma bicarbonate are not easily modified. Some authors have reported improve. ment in chorea, but the most recent records by Gerstley and Wile, ${ }^{5}$ of fifteen closely observed cases, failed to show any advantage in the method at all ; such has been my own experience.

\section{Pyrogenetic Methods}

Since the introduction of the malarial treatment for general paralysis in 1918 by Wagner and Jauregg, many other pyrogenic substances have been employed: inoculation with Treponema hispanicum and with the organism of rat-bite fever ; intravenous injection of typhoid vaccine : and, more recently, intramuscular injections of colloidal sulphur.

Mas de Ayala $^{15}$ was probably the first to apply the method in chorea, using Treponema hispanicum; but mixed typhoid and paratyphoid vaccine proved much more convenient, and remarkable success has been claimed for this measure by Sutton ${ }^{29}$ (1931) and by Trawley, Pepper, and Wathe ${ }^{31}$ (1932). About 250 millions of the mixed organisms are injected, and the dose steadily increased daily. A peak of temperature is produced in about three hours, and the temperature is normal four or five hours later. The method appears to cut short the attack effectively. It must, however, be classed as drastic treatment. The patients are decidedly exhausted and anaemic afterwards, and require a considerable period for convalescence (Mandel ${ }^{14}$ ). It is clearly desirable to find some simpler therapy if possible.

\section{Three Aetiological Factors}

A consideration of the three commonly recognized aetiological factors-rheumatism, nervous strain, and calcium deficiency-has led me to adopt a gentler type of treatment.

\section{RHEUMATISM}

The association between chorea and rheumatic fever is too close to be ignored. Mackenzie, ${ }^{13}$ in 1887, recorded a history of rheumatic fever in 26 per cent. of his cases. Morley Fletcher, ${ }^{18}$ in 1896 , found the incidence to be 26.9 per cent. among the in-patients at St. Bartholomew's. The corresponding figures for endocarditis among chorea patients are: Hughes (1846), 50 per cent.; Mackenzie (1887), 32 per cent. ; Morley Fletcher (1896), 37 per cent.

These figures are still representative of the condition in more modern times. More careful analysis shows also that the severity of the rheumatic lesion varies in parallel with the severity of the chorea. Thus in the same series of chorea cases rheumatic fever occurred in only 19 per cent. of mild out-patient chorea cases, but in 27 per cent. of more severe in-patient types. Similarly, heart murmurs were present in 22 per cent. of mild cases, but in 49 per cent. of those requiring treatment in the wards. The intimate relation between the two conditions can be accepted as established beyond dispute.

\section{Nervous Strain}

It is difficult to discuss this factor on an actuarial basis. A history of fright or of persistent strain from overwork or excitement is given by a large number of the children concerned. The patient is frequently described as alert and bright intellectually before the chorea begins, although powers of attention and application may be seriously impaired later. Sedatives and tranquillity undoubtedly diminish the violence of the movements; even if they do not shorten the attack.

\section{Calcium Deficiency}

In the latter half of the last century Isambard Owen reported that the topographical distribution of chorea seemed to follow that of rickets, and in 1927 the Medical Research Council ${ }^{17}$ reported that general poverty was the only environmental factor which appeared to be operative in the production of the rheumatic troubles of childhood. More detailed analysis proved elusive. 
It has long been known that a lack of calcium leads to increased muscular excitability (Biedemann, ${ }^{1}$ Loeb, ${ }^{11}$ Lucas $^{12}$ ), manifesting itself in spontaneous twitchings, rhythmical contraction, and increased sensitiveness to electrical stimuli. The excitability of the motor cortex also rises as the calcium concentration falls. In man $a$ fall in serum calcium leads to increased electrical excitability of the muscles ending in tetany. Recently Carter-Braine, Spurrell, and Warner ${ }^{32}$ demonstrated increased response of the muscles to galvanic stimulation in chorea, and Warner ${ }^{33}$ has correlated this with a deficiency of calcium in the serum and cerebro-spinal fluid. In his series of carefully controlled cases he shows that in active chorea there is always a calcium deficit, that this is greater in severe cases than in mild ones, and that it is made good completely at the end of the attack. The ionic calcium appears to be the portion affected, so that the percentage fall is more conspicuous in the cerebrospinal fluid than in the blood. In a typical case he found the cerebro-spinal fluid calcium $4.71 \mathrm{mg}$. per $100 \mathrm{c} . \mathrm{cm}$. during the height of a severe attack. During the first month no appreciable clinical headway was made, and the calcium value fell a little to 4.62. A month later the attack had subsided completely, and the calcium had risen to 5.74. The normal value from collected data ranges from 5.1 to $6.5 \mathrm{mg}$. per $100 \mathrm{c.cm}$. (Neustaedter, ${ }^{20}$ Neale $\left.{ }^{19}\right)$. That a disturbance in calcium metabolisin occurs in the condition is firmly established, but its causation is still a matter for research.

\section{Calcium Aspirin}

In the simple substance calcium aspirin we possess the means of dealing with these three aetiological factors simultaneously. It supplies an adequate amount of calcium, produces a useful sedative effect on the brain, and combats the rheumatic element if given in appropriate doses. The drug has been known for many years, but in spite of its attractiveness has never come into general use, because of its instability. It dissolves readily in water (1 gram dissolves in $5 \mathrm{c} . \mathrm{cm}$.), in contrast with the half litre required by acetyl-salicylic acid, and forms a neutral solution suitable for administration by vein (Cambell, ${ }^{3}$ Pritchard, ${ }^{23}$ Burnford ${ }^{2}$ ) or subcutaneously, as well as by mouth or rectum. The solution is almost tasteless, and being neutral does not cause the gastric or bladder irritation so commonly observed when aspirin itself is given (Winter and Richey ${ }^{35}$ ). Its solubility facilitates absorption (Thompson and Dragstedt ${ }^{30}$ ), so that its effects are produced very quickly when given by mouth or rectum.

The difficulty of its instability has at last been overcome. Even simple aspirin exposed to air slowly decomposes with the liberation of pungent acetic acid and irritant free salicylic acid. Contact with water greatly increases the speed of hydrolysis. The simple salts of aspirin contain water of crystallization, which cannot be withdrawn, and hydrolysis is so rapid that the products become unusable before they can reach the patient through the usual channels. ${ }^{30}$. Coplans has recently shown that this water can be "fixed" by the addition of a small proportion of extra calcium. By crystallization from a solution of calcium chloride a form of calcium aspirin is obtained with a stability approximately equal to that of the parent acid aspirin itself, ${ }^{16}$ and completely suitable for general clinical use. Calcium aspirin (Coplans), when taken by the mouth, causes a rise in the calcium content of the blood $\left(\mathrm{Mutch}^{16}\right)$. The satisfactory nature of the clinical results can be judged from the following series of hospital and private cases treated during the last three years. The patients were kept in bed, and those treated in hospital were screened off partially from the rest of the ward. Bed boards and other protective measures were employed as needed. A light, mixed diet was given, and very careful attention paid to the cleanliness of the digestive tract. The only drug employed (exclusive of aperients) was calcium aspirin (Coplans), dissolved in water and administered by mouth. The average daily dose varied up to 45 grains for a child 12 years old.

The nineteen cases treated can be placed in the groups already defined: (1) mild, five cases; (2) moderate, eleven cases; (3) severe, three cases. The rapidity of response did not vary accurately with the original severity of the choreic movements ; mild cases sometimes proved more resistant than severe ones. The criterion of cure or arrest taken by various authors is not always the same. To remove all ambiguity in the cases under discussion the attack was not registered as over until the condition had so far improved that an average medical man would have had difficulty in diagnosing the case as one of chorea at all. Spontaneous movements had ceased. Voluntary movements were of average accuracy, and the patient could sustain a steady hand-grip for a minute or more without fluctuation.

\section{CASE History}

One typical case (Case 12) will be quoted, and the rest will be summarized in a table.

A girl, aged 16, was admitted on October 28th, 1932, for chorea. First attack four years ago; tonsillectomy three years ago; second attack two years ago. Present attack began two days before admission. Movements were violent, and involved all parts of the body. Boards were fixed to the sides of the bed to prevent the patient from falling out. Voluntary movements could not be performed usefully. A slight systolic bruit could be heard at the apex, but there was no evidence of active endocarditis. Temperature almost normal. No joint pains.

October 26th: Onset of attack. October 28th: Calcium aspirin (Coplans) 15 grains t.d.s., given daily. November 7th: Movements almost disappeared; bed boards removed; could feed and dress herself with ease. November 11th: No movements discernible ; impossible to demonstrate the case as one of chorea.

Complete arrest was achieved after fourteen days of treatment and within sixteen days of the onset of a severe attack. The extreme limits recorded for spontaneous cure in such cases are thirty to 180 days, and the average is sixty-seven.

Table of Cases

\begin{tabular}{|c|c|c|c|c|c|c|c|}
\hline 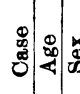 & Group & Attack & $\mid \begin{array}{c}\text { Maxi- } \\
\text { myrexia } \\
\text { myrexia }\end{array}$ & Heart & Joints & $\begin{array}{l}\text { Daily } \\
\text { Dose }\end{array}$ & $\begin{array}{c}\text { Time } \\
\text { Required } \\
\text { for Arrest }\end{array}$ \\
\hline 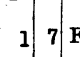 & Mild & 1 & $99.2^{\circ}$ & Normal & Normal & $\underset{30}{\text { grains }}$ & $\operatorname{days}_{12}$ \\
\hline $212 \mathrm{~F}$ & Severe & 1 & $98.8^{\circ}$ & $\begin{array}{c}\text { Apical systolic } \\
\text { bruit }\end{array}$ & $"$ & 45 & 16 \\
\hline $\begin{array}{ll}3 & 9 \\
\end{array}$ & Moderate & 1 & $99.8^{\circ}$ & Norma1 & $"$ & 30 & 10 \\
\hline $414 \mathrm{~F}$ & Mild & 2 & $101.0^{\circ}$ & $\begin{array}{c}\text { Apical systolic } \\
\text { bruit }\end{array}$ & Pains & 60 & 19 \\
\hline $5 \mid \mathbf{l 1}$ &.$"$ & 2 & $98.6^{\circ}$ & Norma1 & Normal & 45 & 9 \\
\hline 69 & Moderate & I & $102.6^{\circ}$ & Endocarditis & " & 30 & 46 \\
\hline $713 \mathrm{M}$ & $"$ & 1 & $99.4^{\circ}$ & Norma1 & " & 45 & 20 \\
\hline $812 \mathrm{~F}$ & " & 3 & $98.4^{\circ}$ & " & " & 45 & 8 \\
\hline $98 \mathrm{M}$ & $"$ & 1 & $99.0^{\circ}$ & . & ". & 30 & 12 \\
\hline $106 \mathrm{~F}$ & " & 1 & $99.8^{\circ}$ & Apical systolic & 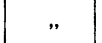 & 25 & 14 \\
\hline $10 \mathrm{~F}$ & Mild & 1 & $101.4^{\circ}$ & Normal & Pains & 30 & 28 \\
\hline $1216 \mathrm{~F}$ & Severe & 3 & $98.8^{\circ}$ & " & Normal & 45 & 14 \\
\hline $1312 \mathrm{~F}$ & Moderate & 2 & $99.2^{\circ}$ & " & " & 45 & 21 \\
\hline 149 & $"$ & 1 & $101.2^{\circ}$ & " & Pains & 30 & 16 \\
\hline $17 \mathrm{~F}$ & $"$ & 2 & $98.2^{\circ}$ & $\begin{array}{c}\text { Apical systolic } \\
\text { bruit }\end{array}$ & Normal & 60 & 15 \\
\hline $1611 \mathrm{M}$ & Severe & 1 & $99.6^{\circ}$ & Normal & Pains & 45 & 11 \\
\hline 178 & Moderate & 1 & $102.0^{\circ}$ & 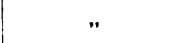 & $"$ & 30 & 13 \\
\hline $1812 \mathrm{~F}$ & $"$ & 1 & $100.6^{\circ}$ & Endocarditis & Normal & 45 & 34 \\
\hline $19|9| \mathrm{F}$ & Mild & 1 & $99.4^{\circ}$ & $\underset{\text { bruit }}{\text { Apical systolic }}$ & $"$ & 30 & 7 \\
\hline
\end{tabular}


The average time taken to control these patients was seventeen days, and the limits seven to forty-six days respectively; figures which compare very favourably indeed with the average expectation of thirty-five days for mild chorea cases and the sixty-seven days for severe ones referred to in the earlier part of this paper. The drug diminished the discomforts of the patients at all stages of the treatment, and did not produce any of that mental depression which accompanies the use of chloretone and certain other hypnotics. There was no undue drowsiness or digestive derangement. There was no relapse or secondary exhaustion when the drug was finally withdrawn.

\section{Conclusions}

Calcium aspirin (Coplans)* affords a method of treating chorea without occasioning exhaustion, discomfort, or risk to the patient. It is less toxic ${ }^{16}{ }^{30}$ than acetyl-salicylic acid itself, and is free from the irritant action of the parent substance on the stomach and bladder. It is freely soluble, almost tasteless, and is rapidly absorbed. It has a triple action: (1) anti-rheumatic, (2) correction of calcium deficiency, (3) sedative to the brain.

The best results are secured when the patient is kept in bed during treatment and protected from undue emotionai and mental stress.

ReFERENCES

' Beidemann, W.: Sitzungsb. der Wien. Akad. der Wissens., 1880, Ixxxii, 3 .

2 Burnford, J.: Lancet, 1931, i, 351

${ }^{3}$ Cambell, A.: British Medical Journal, 1921, ii, 37.

'Dennett, R. H., and Wetchler, S.: Journ. Pediat., 1932, 203.

5 Gerstley, J. R., and Wile, S. A.: Ibid., 1932, 458.

${ }^{6}$ Hefter, E.: Zeit. f. Kinderheilk., 1924, xxxviii, 403

'Hughes, H. M.: Guy's Hospital Reports, 1846, Series 2, iv ; ibid., 1855, Series 3, i.

${ }^{8}$ Husler, J.: Zeit. f. Kinderheilk., 1924, xxxviii, 408.

- Jones, T. D., and Jacobs, J. L.: Journ. Amer. Med. Assoc., 1932, xcix, 18.

${ }^{10}$ Keller, R.: Deut. med. Woch., 1928, lxiv, 1880.

${ }^{11}$ Loeb, J.: Beit. z. Physiol., Fest. I. Adolf Fick, 1899

${ }^{12}$ Lucas, K. : Journ. Physiol., 1910, xl, 225

${ }^{13}$ Mackenzie, S.: British Medical Journal, 1887, i, 425.

${ }^{14}$ Mandel, L.: Ibid., 1933, ii, 78

${ }^{15}$ Mas de Ayala: Ann. Fac. Med. Monte Video, 1930, xxi, 73

${ }^{16}$ Mutch, N.: Journ. Pharmacol. and Exper. Therap., 1934, li, 112

17 Medical Research Council Special Report, Rheumatism, 1927, Series 114, p. 94.

${ }^{18}$ Fletcher, H. Morley: St. Bart's Hosp. Reports, 1897, xxxii, 383.

${ }^{19}$ Neale, A. V., and Esslemont, M. S.: Arch. Dis. Child., 1928, xvi, 243.

${ }^{20}$ Neustaedter, M., Hala, W., and Tobstoouchow, A.: Journ. Amer. Med. Assoc., 1925, lxxxv, 347.

${ }_{21}$ Pilcher, J. M., and Gerstenberger, H. J.: Amer. Joum. Dis. Child., 1930, xl, 1239.

22 Piltz, K.: Arch. f. Kinderheilk., 1927, lxxxii, 810.

${ }^{23}$ Pritchard, H.: British Medical Journal, 1927, i, 794

${ }^{24}$ Pye-Smith, P. H.: Guv's Hospital Reports 1874, Series 3, xix.

${ }^{25}$ Roeder, F.: Therap. Monats., 1919, xxxiii, 54.

${ }^{26}$ Schmal, S. : Deut. med. Woch., 1925, li, 1439.

${ }^{27}$ Sée: De la Chorée et les Affections Nerveuses, Paris, 1851.

28 Shaw, B.: Arch. Dis. Child., 1929, iv, 155.

${ }^{29}$ Shaw, B.: Arch. Dis. Child., 1929, iv, 155.

so Thompson, H. E., and Dragstedt, C. A.: Joum. Amer. Pharm. Assoc., 1933, xxii, 1096

$"$ Trawley, J. M., Pepper, M., and Wathe, L. E. : Calif. and West. Med., 1932, xxxvi, 346.

22 Warner, E. C., Spurrell, W. R., and Carter-Braine, J. F.: Guy's Hospital Reports, 1929, lxxix, 473.

ss Warner, E. C.: Lancet, 1930, i, 339

s4 Weinfeld, G. F., and Cohen, R.: Journ. Pediat., 1932, 210 ; Journ. Amer. Med. Assoc., 1932, xcix, 33.

winter, J. E., and Richey, C. H.: Journ. Pharmacol. and Exper. Therap., 1931, xlii, 2, 179.

* Calcium chloride is present in this stabilized preparation to an extent approximating to the formula $\left[\mathrm{C}_{6} \mathrm{H}_{4}\left(\mathrm{OCOCH}_{3}\right) \mathrm{CO}_{2}\right]_{2} \mathrm{Ca}_{2} \mathrm{H}_{2} \mathrm{O}+1 / 3 \mathrm{CaCl}_{2}$

The Health and Cleanliness Council (5, Tavistock Square, W.C.1) has issued a revised edition of its pamphlet first issued in 1926, incorporating suggestions for a local health and cleanliness campaign. Supplies are available for distribution free of charge, and applications for copies should be addressed to the secretary, Miss Norah March, B.Sc., at the address given above. The advisory board of the council consists of Dr. George F. Buchan (chairman), Dr. Sophia Friel, Miss J. Halford, Professor H. R. Kenwood, and Dr. Eric Pritchard.

\section{THROMBOSIS OF THE PENIS AND URETHRAL HAEMORRHAGE *}

\author{
BY
}

CLIFFORD MORSON, O.B.E., F.R.C.S.

PRESIDENT, SECTION OF UROLOGY, ROYAL SOCIETY OF MEDICINE

Thrombosis may occur either in the veins of the penis or in the corpora cavernosa. The latter consist of spaces which fill with arterial blood when the penis is in a state of erection. This is only a part of the physiological process leading to enlargement of the organ. The glans is the terminal portion of the corpus spongiosum, and also distends with blood in the presence of sexual excitement.

The causes of a persisting enlargement of the penis are either nervous or vascular, and each can be recognized by the shape of the organ. Priapism is due to a nervous lesion, and the appearance of the penis is similar to that seen in the physiological state. On the other hand, thrombosis of the corpora cavernosa leads to the formation of a hard and tense swelling of the whole organ, except the glans. If the clotting is more extensive in one corpus than the other deviation occurs, and the penis is bent to the side which is more thrombosed. There are three diseases which may lead to the clotting of the blood in the cavernous spaces. They are malignant disease of the left kidney, lymphatic leukaemia, and arteriosclerosis. Whichever the cause, the condition is fortunately rare.

The explanation of the reason why thrombosis of the corpora cavernosa occurs in carcinoma of the left kidney is purely anatomical. The spermatic vein on this side of the body enters the renal vein. If the latter becomes blocked with growth at the point of entry of this tributary, stagnation of the blood occurs in the penis and left testicle, so that not only does pseudopriapism occur, but there is a temporary swelling of the latter due to the block in the pampiniform plexus. These veins can be felt as a hard mass in the inguinal canal. No original observations can be made on penile thromboris due to lymphatic leukaemia, for the writer has never seen a case. However, most textbooks describe it as a complication of this blood disease, and it must be accepted as a fact unless proved to the contrary.

With regard to arteriosclerosis as a causal agent, two cases of thrombosis of the penis have been investigated in which the local lesion has been proved to be due to arterial disease. A study of the literature reveals that a considerable number have been described in which the cause is stated to be unknown. More accurate observation would have cleared up the mystery. In view of the fact that the nipple of a female breast consists of erectile tissue it is probable that thrombosis has occurred in this organ also in relation to arterial disease, but such a case has yet to be recorded.

\section{Thrombosis: Case Records}

The details of the two cases of thrombosis of the penis are as follows:

The first case to be carefully investigated was that of a man, aged 35, who was admitted to Whipps Cross Hospital with the whole of the penis, apart from the glans, swollen and hard. The enlargement extended back to the bulb. The history was that the swelling had been of gradual onset, a period of three days having elapsed before it reached its full size. During this time repeated coitus had failed to produce any change in the organ. On admission the patient was in considerable distress, and complained of difficulty in micturition. There was no pain. The medical cfficer,

* A communication read befcre the Dutch Urological Association at Amsterdam, April, 1934. 